\title{
Preparation of bimodal porous alumina using propylene glycol oligomers
}

\author{
Ryoji TAKAHASHI ${ }^{\dagger}$, Akiko ONISHI*, Fumiya SATO and Makoto KURAMOTO** \\ Department of Chemistry, Graduate School of Science and Engineering, Ehime University, \\ 2-5 Bunkyo-cho, Matsuyama 790-8577, Japan \\ *Department of Chemistry, Faculty of Science, Ehime University, 2-5 Bunkyo-cho, Matsuyama 790-8577, Japan \\ ${ }^{* *}$ Advanced Research Support Center, Ehime University, 2-5 Bunkyo-cho, Matsuyama 790-8577, Japan
}

\begin{abstract}
Bimodal porous alumina was prepared from the solution with aluminum chloride and 1,2-propylene oxide by adding propylene glycol oligomers (PPG). Because of hydrophobic nature of PPG, the addition of PPG induces phase separation during sol-gel reaction, and macroporous morphologies are formed by fixing transitional structure of phase separation. Since ethanol works as a co-solvent, the macropore size of the obtained gel can be increased by decreasing ethanol content. Change in the concentration of other constituents such as PPG has also an effect to control morphologies through changing the timing of phase separation and sol-gel transition.
\end{abstract}

(C2017 The Ceramic Society of Japan. All rights reserved.

Key-words : Bimodal porous alumina, Phase separation, Poly(propylene glycol), Propylene oxide, Spinodal decomposition

[Received March 28, 2017; Accepted June 5, 2017]

\section{Introduction}

Porous alumina has widely been used as a catalyst, a catalyst support, an adsorbent, and so on because of its high surface area. ${ }^{1)-4)}$ Although some materials such as silica ${ }^{5)}$ and activated carbon $^{6}$ have higher surface area than alumina, alumina is much superior to these materials in thermal and chemical stability. ${ }^{7), 8)}$ Porous alumina was usually prepared by precipitation method where aluminum hydroxides or aluminum oxo-hydroxides were precipitated by neutralization of aluminum salt solution with base such as ammonia solution. ${ }^{4)}$ Hereinafter we call these two compounds aluminum hydroxides without distinction. Sol-gel method using aluminum alkoxide was also investigated to prepare alumina ceramics and alumina gels. ${ }^{9), 10)}$ However, high reactivity of aluminum alkoxide makes it difficult to control sol-gel reaction. ${ }^{4)}$ In addition, most of the porous alumina thus prepared has only mesopores.

Gash et al. reported the preparation of alumina gel from aluminum chloride hexahydrate $\left(\mathrm{AlCl}_{3} \cdot 6 \mathrm{H}_{2} \mathrm{O}\right)$ in the presence of propylene oxide (PO). ${ }^{11), 12)}$ In the solution, $\mathrm{PO}$ works as a proton scavenger, that is $\mathrm{PO}$ reacts with $\mathrm{HCl}$ for decreasing proton concentration. ${ }^{13)}$ Therefore, the solution $\mathrm{pH}$ increases uniformly with the consumption of proton, and the solution loses its mobility after the $\mathrm{pH}$ increases higher enough for gelation. Because of controlled sol-gel transition in the $\mathrm{AlCl}_{3}-\mathrm{PO}$ system, monolithic gel could be obtained easily. ${ }^{11)}$ Tokudome et al. reported the preparation of alumina with both macropores and mesopores by inducing phase separation concurrently with sol-gel transition of aluminum hydroxides in the $\mathrm{AlCl}_{3}-\mathrm{PO}$ system. ${ }^{14)}$ The material is obtained by freezing transitional structure of phase separation by gelation, and has typical bimodal porous structures with hierarchically arranged macropores and mesopores. A material with hierarchical bimodal pore structures is quite important in

Corresponding author: R. Takahashi; E-mail: rtaka@ehime-u.ac.jp * Preface for this article: Dol http://doi.org/10.2109/jcersj2.125.P10-1 separation and catalysis. For example, Nakanishi et al. reported the preparation of monolithic columns made of bimodal porous silica for high performance liquid chromatography and showed their excellent performance in the separation. ${ }^{15)}$ We prepared bimodal porous silica-alumina and showed that the bimodal porous structure is effective in solid catalytic reaction with high reaction rate. ${ }^{16)}$ The bimodal porous alumina is also expected to be used in wide practical applications, such as a catalyst support in steam-reforming of methane where the reaction rate is quite high because of high reaction temperature. ${ }^{17)}$ In the method reported by Tokudome et al., however, they used poly(ethylene oxide) (PEO) with a molecular weight of 1 million (PEO1M) for inducing phase separation. ${ }^{14)}$ Because of high viscosity of a solution with PEO1M, it takes long time for homogeneous dissolution of PEO1M. Thus, the use of PEO1M is considered to be a drawback in the practical applications.

In this work, we focused on the poly(propylene glycol) (PPG). Although PPG has low water solubility, ethanol was used in the sol-gel process of $\mathrm{AlCl}_{3}-\mathrm{PO}$ system. Because PPG is liquid substance and dissolves in ethanol well, we can expect that PPG also works as a phase separation inducer in the sol-gel process. PPG use has a large advantage in the processing because only a several seconds are required for homogeneous mixing. In this work, we report the preparation of porous alumina with both macropores and mesopores by using a small molecular weight PPG.

\section{Experimental}

In the preparation of porous alumina, $\mathrm{AlCl}_{3} \cdot 6 \mathrm{H}_{2} \mathrm{O}$ was used as an alumina source. PO was used as a proton scavenger. PPG with an average molecular weight of 400 , which is an oligomer of propylene glycol with 6 or 7 units in average, was used for inducing phase separation during sol-gel reaction. Ethanol was used as a solvent. All the chemicals were purchased from Wako Pure Chemical Industries, Ltd., and were used without further purification. 
Firstly, $\mathrm{AlCl}_{3} \cdot 6 \mathrm{H}_{2} \mathrm{O}$ was dissolved in a mixed solution of ethanol and water. After the dissolution of the aluminum salt, PPG and PO were added in order. After the solution had become homogeneous, the solution was kept at $40^{\circ} \mathrm{C}$ for 1 day in a closed glass container for gelation. The obtained wet gel was dried at $50^{\circ} \mathrm{C}$ for ca. 1 week to be a dried gel. The dried gel was heated at $600^{\circ} \mathrm{C}$ for $2 \mathrm{~h}$ with heating rate of $100^{\circ} \mathrm{C} / \mathrm{h}$. The starting composition is $\mathrm{AlCl}_{3} \cdot 6 \mathrm{H}_{2} \mathrm{O}: \mathrm{PO}$ :water:ethanol:PPG $=4.32: 3.11: a: b: c$ in weight ratio. We fixed the ratio of $\mathrm{AlCl}_{3} \cdot 6 \mathrm{H}_{2} \mathrm{O}: \mathrm{PO}$ to be $1: 3$ in molar ratio. Gels were prepared by changing the composition of $a, b$, and $c$, and gelation behaviors and pore structures of obtained gels were observed.

Scanning electron microscope (SEM, SM200, TOPCON) was used for observation of fractured surface of dried gels. $\mathrm{Hg}$ porosimetry (poremaster33P, Quantchrome) and nitrogen adsorption at $-196^{\circ} \mathrm{C}$ (Autosorb1MP, Quantachrome) were adopted for evaluation of pore structures for heated samples. Prior to the nitrogen adsorption measurement, each sample was pretreated at $300^{\circ} \mathrm{C}$ for $1 \mathrm{~h}$ under vacuum. The BET and the Dollimore-Heal methods were used for analyzing isotherms. Thermal gravimetrydifferential thermal analysis (TG-DTA; EXSTAR TG/DTA6200, Seiko Instruments Inc.) was performed for a dried gel to observe evolution of samples in heating. The X-ray diffraction (XRD) patterns were recorded on an XRD7000 (Shimadzu) using $\mathrm{Cu} \mathrm{K} \alpha$ radiation $(\lambda=0.154 \mathrm{~nm}$, with $40 \mathrm{kV}, 30 \mathrm{~mA})$. Proton nuclear magnetic resonance ( $\left.{ }^{1} \mathrm{H} \mathrm{NMR}\right)$ spectra were recorded on AVANCE III 500 (Bruker) for determining the products of PO reaction.

\section{Results}

Figures 1 and $\mathbf{2}$ show SEM images of a fractured surface of the dried gels prepared. Hereinafter we used the word "gel" for "dried gel". At appropriate solution compositions, it is recognized that macroporous materials are formed. The changes in the
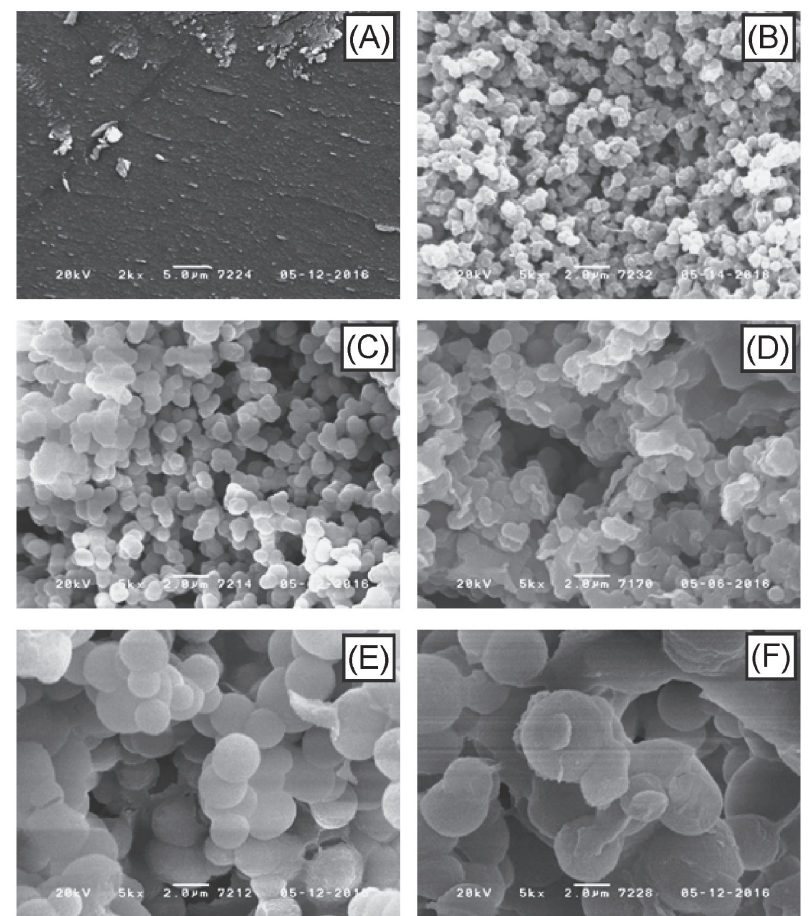

Fig. 1. SEM images of fractured surface of the dried gels prepared by changing ethanol content. The weight ratio in preparation is $\mathrm{AlCl}_{3} \cdot 6 \mathrm{H}_{2} \mathrm{O}$ : PO:water:ethanol:PPG $=4.32: 3.11: 4.00: b: 0.25$, where $b=$ (A) 3.70, (B) 3.48, (C) 3.26, (D) 3.04, (E) 2.83, (F) 2.61. morphology of the materials with ethanol and PPG contents are shown in Figs. 1 and 2, respectively. When the ethanol content is higher enough, homogeneous transparent alumina gels are formed, and no macroporous structure is found on the fractured surface of these gels by SEM observation [Fig. 1(A)]. With the decrease in the ethanol content, gels become white opaque, and macroporous morphology is formed [Figs. 1(B)-1(F)]. We define the domain size as an average of the sum of skeleton diameter and adjoining pores diameter. The domain size increases with the decrease in ethanol content. At the low ethanol content, inorganic phase precipitated before gelation. Change in the PPG content has an opposite effect (Fig. 2). The domain size increases with the increase in the PPG content. The effect of the change in the water content on domain size is relatively smaller than that of the changes in PPG and ethanol contents (photos are not shown). On the other hand, most of the samples have low connectivity in the gel skeleton. When the domain size becomes larger, particularly, morphology turns to the aggregates of spherical particles. Samples with these morphologies are mechanically weak, and monolith samples are easily broken even by a touch with a spatula. Some samples with relatively small domain size have high stiffness. In the pore size distribution in micrometer range for these stiff samples measured by the Hg porosimetry (Fig. 3), there is a sharp peak at the size almost the same as that of macropores observed by the SEM for the each sample. It is ensured that macropore size can be controlled by the change in the solution composition for the system with PPG.

Here, it should be noted that some samples prepared with no PPG also have macropores as shown in Fig. 2(A). In a solution with $\mathrm{PO}$, ring-opening reaction of epoxy-ring in $\mathrm{PO}$ proceeds under acidic conditions. ${ }^{13)}$ Firstly, proton attacks on bridging oxygen.

$$
\stackrel{\mathrm{C}_{\mathrm{CH}_{3}}}{\longrightarrow} \mathrm{H}^{+} \stackrel{\mathrm{H}_{+}^{+}}{\mathrm{O}_{\mathrm{CH}_{3}}}
$$

Then, PO is hydrolyzed into 1,2-propanediol (PDO) when chloride ion is absent.
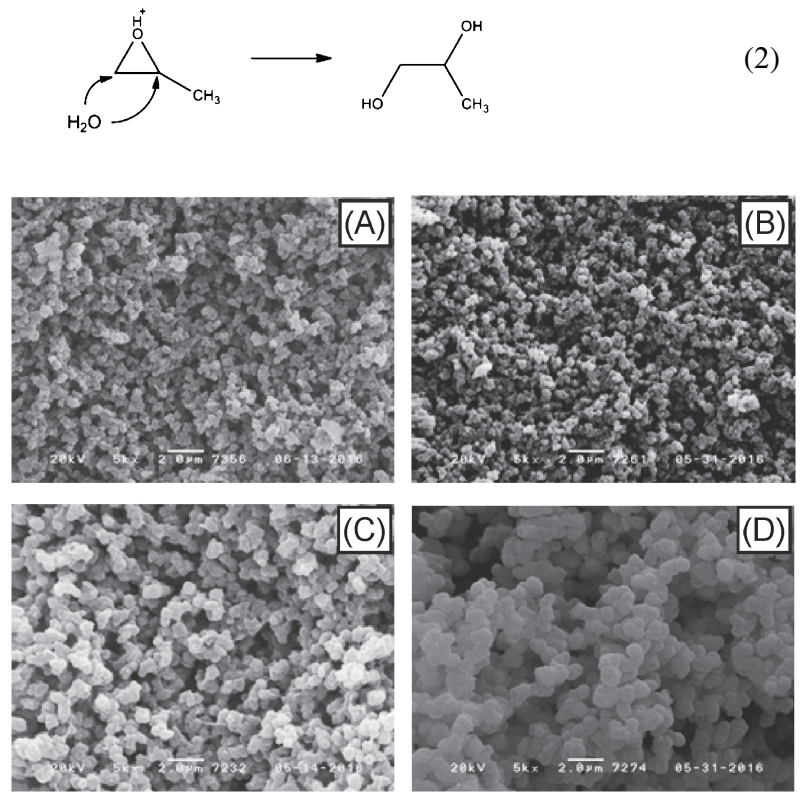

Fig. 2. SEM images of fractured surface of the dried gels prepared by changing PPG content. The weight ratio in preparation is $\mathrm{AlCl}_{3} \cdot 6 \mathrm{H}_{2} \mathrm{O}$ : PO:water:ethanol:PPG $=4.32: 3.11: 4.00: 3.48: c$, where $c=(A) \quad 0$, (B) 0.15 , (C) 0.25 , (D) 0.30 . 


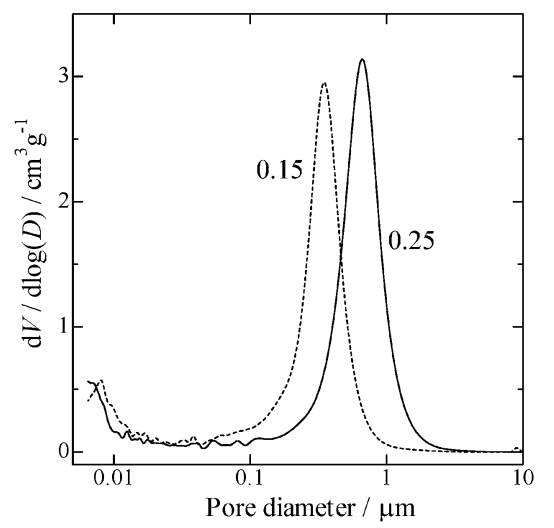

Fig. 3. Pore size distribution curves measured by $\mathrm{Hg}$ porosimetry for heated samples prepared with the weight ratio of $\mathrm{AlCl}_{3} \cdot 6 \mathrm{H}_{2} \mathrm{O}: \mathrm{PO}$ :water: ethanol:PPG $=4.32: 3.11: 4.00: 3.48: c$, where the numbers on the curves are the values of $c$. $V$ : pore volume, $D$ : pore diameter.

Under the presence of chloride ion, on the other hand, addition of $\mathrm{HCl}$ to $\mathrm{PO}$ resulting in chloropropanol (CPO) takes precedence over the hydrolysis.

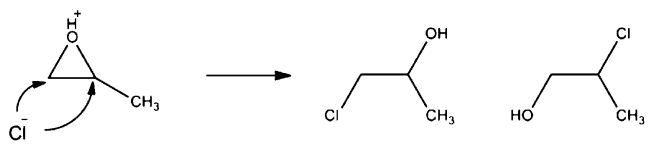

Because aqua complex of $\mathrm{Al}$ is a weak acid, $\mathrm{HCl}$ addition to $\mathrm{PO}$ is considered to proceed preferentially in the $\mathrm{AlCl}_{3}-\mathrm{PO}$ system. ${ }^{13)}$ In the solution, however, other reaction such as hydrolysis and polymerization forming PDO and PPG, respectively, may occur. If polymerization of PO occurs, not only the PPG added but also PPG produced from PO will affect the morphology of the gels. In order to ensure the reaction products of PO during sol-gel reaction, we measured ${ }^{1} \mathrm{H}$ NMR spectra. Because the gelation occurred quickly by addition of PO, we prepared two hypothetical reacting solution: one contains water, ethanol, $\mathrm{PO}$ and $\mathrm{HNO}_{3}$, and the other contains water, ethanol, $\mathrm{PO}, \mathrm{HCl}$ and $\mathrm{NaCl}$. We have to prepare the two hypothetical reacting solutions because we cannot obtain a reagent of CPO probably because of its unstability. Figure 4 shows ${ }^{1} \mathrm{H}$ NMR spectra of the hypothetical reacting solutions together with those of reference samples with PDO, and with PPG. Most of the resonance peaks became broad or multiplet due to the variation in the structure, steric conformation and/or environment. Peaks at ca. $1.5 \mathrm{ppm}$ are assigned to protons in methyl groups of ethanol, PO, PDO, CPO and PPG. Peaks at $>4.5 \mathrm{ppm}$ are assigned to protons in $\mathrm{OH}$ of water and alcohols. A multiplet peak at $3.9 \mathrm{ppm}$ is assigned to protons in methylene group in ethanol, and three peaks between 2.5 and $3.5 \mathrm{ppm}$ are assigned to protons bonding to carbons in epoxy ring.

In the spectrum (a), multiplet peaks at 3.73 and $4.11 \mathrm{ppm}$ are ascribed to PDO. In addition to the two peaks, three other peaks are observed at 4.20, 3.75-3.80 and $3.64 \mathrm{ppm}$ in (b) with PPG. The presence of these 5 peaks can be an evidence of the formation of PPG. It should be noted that the intensity ratio of the 5 peaks would vary depending on the polymerization site, head to head, tail to tail, or head to tail. The spectra (c) and (d) are hypothetical reacting solution with water, ethanol, $\mathrm{PO}, \mathrm{HCl}$ and $\mathrm{NaCl}$, where sample (c) contains a half amount of PO compared to (d). Because no peak is observed at $4.11 \mathrm{ppm}$ ascribed to PDO and PPG in (c), it is considered only CPO is formed from PO when the PO content is small. The peaks at 3.79, 4.26 and 4.38 ppm can be ascribed to $\mathrm{CPO}$, and the presence of peaks at 4.26

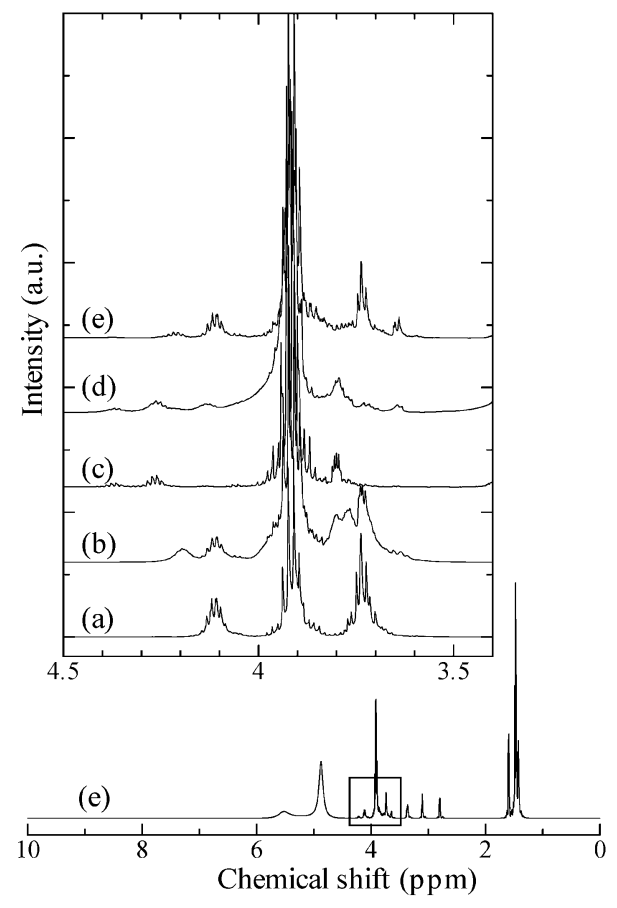

Fig. 4. ${ }^{1} \mathrm{H}$ NMR spectra for the solution with (a) water, ethanol and $\mathrm{PDO}$, (b) water, ethanol and PPG, (c) water, ethanol, $\mathrm{PO}, \mathrm{HCl}$ and $\mathrm{NaCl}$ with a half $\mathrm{PO}$ content compared to (d), (d) water, ethanol, $\mathrm{PO}, \mathrm{HCl}$ and $\mathrm{NaCl}$, (e) water, ethanol, $\mathrm{PO}$, and $\mathrm{HNO}_{3}$.

and $4.38 \mathrm{ppm}$ would be an evidence of the formation of CPO. The spectrum (e) for solution with water, ethanol, $\mathrm{PO}$ and $\mathrm{HNO}_{3}$ shows five peaks ascribed to PPG. Because the peaks at 3.73 and $4.11 \mathrm{ppm}$ ascribed to PDO are large, the reaction products of PO in the solution without chloride ion are considered to be PDO and PPG. In the spectrum (d) with normal PO content, we can see all these peaks. Thus, we can consider that the reaction products of $\mathrm{PO}$ in the solution with water, ethanol, $\mathrm{PO}, \mathrm{HCl}$ and $\mathrm{NaCl}$ are mixture of PDO, CPO and PPG. In addition, substantial amount of $\mathrm{PO}$ is found to remain in the solution. Although it is difficult to directly measure the compositions in reacting solution with $\mathrm{Al}$ salts because of fast gelation, reactions similar to those occurring in the hypothetical solution are considered to take place in the $\mathrm{AlCl}_{3}-\mathrm{PO}$ system, too.

Figure 5 shows profiles of TG and DTA for a dried sample. Up to $150^{\circ} \mathrm{C}$, endothermic weight decrease occurs followed by exothermic weight decrease between 150 and $600^{\circ} \mathrm{C}$. The endothermic weight decrease at $<150^{\circ} \mathrm{C}$ is attributed to the vaporization of ethanol, water and products of $\mathrm{PO}$ reaction such as $\mathrm{PDO}$ and CPO. The exothermic weight decrease can be attributed to the oxidation of PPG. Dehydration from aluminum hydroxide to alumina is not clearly observed in TG-DTA probably because it overlaps with the oxidation of PPG.

Figure 6 shows a $\mathrm{N}_{2}$ adsorption isotherm for a heated sample together with pore size distribution in nanometer range. The macroporous alumina also has mesopores with the size of ca. 5$10 \mathrm{~nm}$ and high specific surface area of $243 \mathrm{~m}^{2} \mathrm{~g}^{-1}$. This mesopore structure is similar to that reported by Tokudome et al. for alumina prepared by using PEO. ${ }^{14)}$ Figure 7 shows change in the XRD patterns with heating temperature. The obtained alumina gel is amorphous up to $700^{\circ} \mathrm{C}$. The gel transforms to $\gamma$-alumina over $700^{\circ} \mathrm{C}$. Over $1100^{\circ} \mathrm{C}$, the gel transforms again to $\alpha$-alumina. This crystallization behavior is also similar to that reported previously for alumina prepared by using PEO. ${ }^{14)}$ 


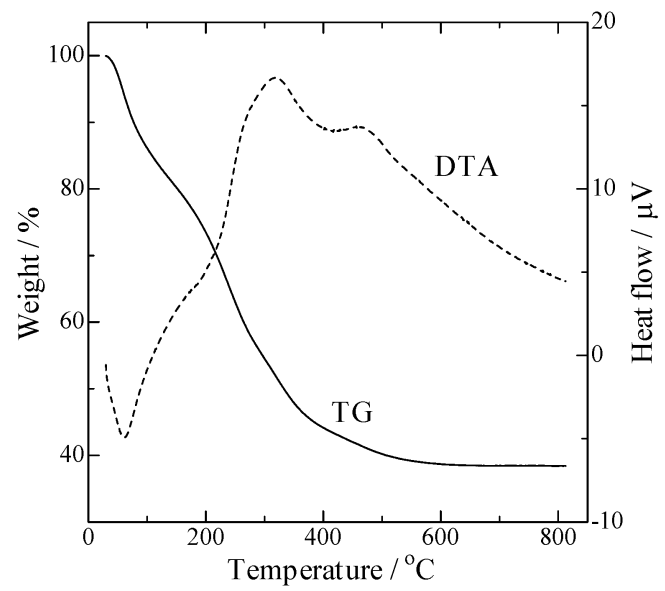

Fig. 5. TG and DTA profiles of the dried gels prepared with the weight ratio of $\mathrm{AlCl}_{3} \cdot 6 \mathrm{H}_{2} \mathrm{O}: \mathrm{PO}$ :water:ethanol:PPG $=4.32: 3.11: 4.00: 3.48: 0.25$.

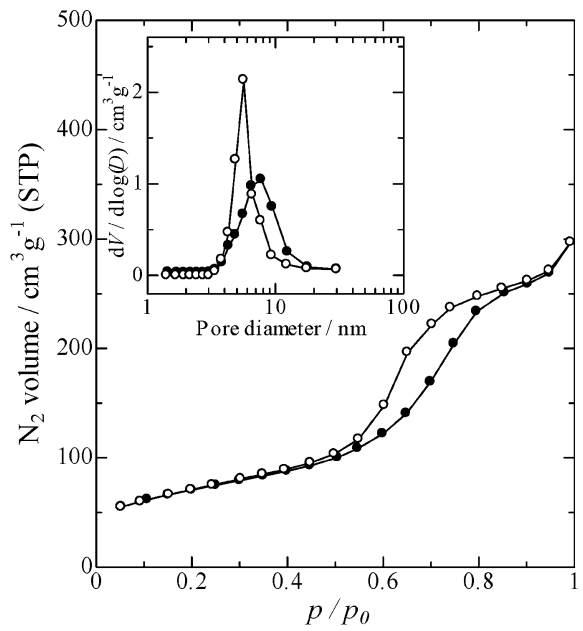

Fig. 6. $\mathrm{N}_{2}$ adsorption isotherm and pore size distribution (inset) of the the heated gels with the weight ratio of $\mathrm{AlCl}_{3} \cdot 6 \mathrm{H}_{2} \mathrm{O}: \mathrm{PO}$ :water:ethanol: $\mathrm{PPG}=4.32: 3.11: 4.00: 3.48: 0.25 . V$ : pore volume, $D$ : pore diameter, $p: \mathrm{N}_{2}$ pressure, $p_{0}$ : saturated $\mathrm{N}_{2}$ pressure.

\section{Discussion}

In this work, we assured that alumina with macroporous morphology is obtained in the sol-gel reaction of $\mathrm{AlCl}_{3} \cdot 6 \mathrm{H}_{2} \mathrm{O}-$ PO system in the presence of PPG with a small molecular weight of 400 . The size of macroporous morphologies decreases with the increase in the ethanol content. In addition, precipitates formed at the composition with low ethanol content whereas transparent non-macroporous gel formed at the composition with high ethanol content. In the solution, ethanol is considered to be a cosolvent of polymerized aluminum hydroxides and PPG. These structural changes with the change in the solution composition suggest that the macroporous morphologies are formed by freezing transitional structures of spinodal decomposition. ${ }^{15)}$

In the $\mathrm{AlCl}_{3} \cdot 6 \mathrm{H}_{2} \mathrm{O}$ solution, solution $\mathrm{pH}$ is ca. 2 because aqua complex of $\mathrm{Al}$ shows weak acidity. The solution $\mathrm{pH}$ gradually increases with the reaction of $\mathrm{PO}$ with $\mathrm{HCl}$ [Eq. (3)], which leads the condensation of aqua complex of $\mathrm{Al}^{4}{ }^{4}$ Condensed $\mathrm{Al}$ complex forms aluminum hydroxides. Because $\mathrm{pH}$ of the solution increases gradually, the aluminum hydroxides become a gel with the progress of the condensation. Mixing entropy of the solution decreases during the condensation of aluminum hydroxides, and

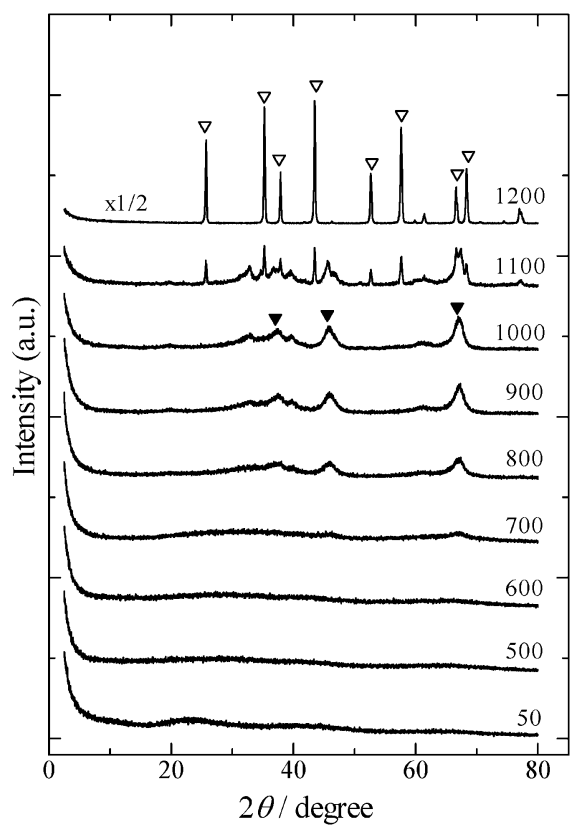

Fig. 7. XRD patterns of the sample heated at different temperature The weight ratio in preparation is $\mathrm{AlCl}_{3} \cdot 6 \mathrm{H}_{2} \mathrm{O}: \mathrm{PO}$ : water:ethanol:PPG = 4.32:3.11:4.00:3.48:0.25. The numbers on the patterns represent the heating temperature $\left({ }^{\circ} \mathrm{C}\right)$. Open triangle: $\alpha$-alumina, closed triangle: $\gamma$ alumina.

phase separation occurs when the mixing free energy becomes positive. ${ }^{15)}$ Usually, however, the solubility of solutes in a sol-gel solution is higher enough to avoiding the phase separation before gelation. Therefore, transparent gels are obtained. Tokudome et al. induced phase separation by adding high molecular weight PEO1M. ${ }^{14)}$ They discussed that decreased mixed entropy by the addition of PEO1M with high molecular weight effectively induces phase separation between condensed aluminum hydroxides and PEO during sol-gel reaction. In this work, we used PPG with low molecular weight instead of PEO. Although PEO is soluble both in ethanol and water, solubility of PPG in water is quite low. In the neutral surfactant Pluronic P123, a triblock copolymer with the structure of PEG-PPG-PEG, for example, PPG chain works as hydrophobic groups. It is considered that the addition of PPG in the sol-gel solution effectively increases mixing enthalpy higher enough for inducing phase separation during sol-gel reaction.

In order to clarify the phase relation, we drew a pseudo ternary phase diagram in Fig. 8: one end is $\mathrm{Al}(\mathrm{OH})_{3}$, other end is the sum of PO and PPG, and the other one is the solvent which contains water and ethanol together with other inorganic groups from raw materials. Here, we summarize PO and PPG in a one end in the phase diagram because substantial amount of PPG is formed through the polymerization of PO as suggested by ${ }^{1} \mathrm{H}$ NMR. In fact, macroporous morphology is formed in a solution without PPG at appropriate compositions probably because the PPG formed by the condensation of PO and/or unreacted PO affects the phase stability. Homogeneous gels are obtained at the compositional region with high solvent amount, and phase separation tends to occur at that with low solvent amount. This means that the solvent work as a co-solvent between PPG and aluminum hydroxide polymers. We can draw a phase boundary line between single-phase region and two-phases region. Here it should be noted that this phase boundary is a temporary one, because it moves toward region with higher solvent amount with the prog- 


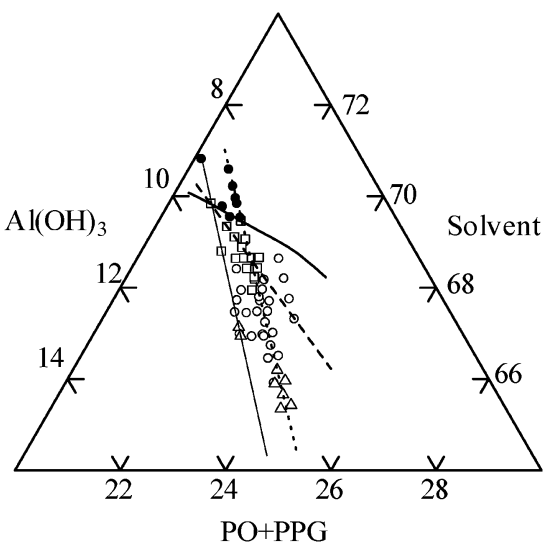

Fig. 8. Pseudo ternary phase diagram. Closed circle: no macropores, square: mutually connected macropores, open circle: particle aggregates, triangle: precipitate formation. Compositional changes for the samples shown in Figs. 1 and 2 correspond to dotted and broken lines, respectively. Solid curve and thin line represent the apparent phase boundary and the composition with the molar ratio of $\mathrm{PO}: \mathrm{Al}=3$, respectively.

ress of the polymerization of aluminum hydroxides. Therefore, the phase boundary line drawn in Fig. 8 only represents the boundary when the solution becomes a gel. If the mixing free energy becomes positive after gelation, no phase separation takes place due to restricted mobility.

As shown in Figs. 1 and 2, most of macroporous alumina gels show low connectivity in gel skeleton. In the spinodal decomposition, mutually connected concentration fluctuation appears in a homogeneous solution, and its amplitude and size increase with time. ${ }^{15)}$ During such growth of phase separation morphology, minor phase segregates when the volume ratio of separating two phases differs from 1:1. In this work, the mutually connected morphology is observed vicinity to the phase boundary (Fig. 8). Because the domain size of the gel is smaller than that reported by Tokudome et al., ${ }^{14)}$ the gel morphology is obtained by fixing just after phase separation. As observed in silica-zirconia, ${ }^{18), 19 \text { ) }}$ macroporous skeleton does not have smooth surface when the time lag between phase separation and gelation is small because of restricted mobility by gelation. In addition, particle aggregate structures are observed in wide compositional range in Fig. 8. This result suggests that the gels were prepared with the composition where the aluminum hydroxide became minor phase. If we can prepare the samples at the composition with low content of (PO and PPG), mutually connected morphology with large domain size would be obtained. It is difficult, however, to prepare the samples with such composition because of the restriction in the molar ratio of PO:Al. We cannot decrease the ratio largely from 3 , because incomplete $\mathrm{HCl}$ consumption makes it difficult to the solution becoming gel.

We succeeded to prepare hierarchically arranged bimodal porous alumina by inducing phase separation in $\mathrm{AlCl}_{3}-\mathrm{PO}$ system by adding PPG. The alumina has mesopore structure similar to those reported. The use of PPG has a large advantage in preparation because of convenient procedure without dissolving high-molecular weight organic polymer. However, further inves- tigation will be necessary in order to improve gel skeleton connectivity and to clarify the phase relation in phase separation.

\section{Conclusion}

Bimodal porous alumina has been prepared in the $\mathrm{AlCl}_{3}-\mathrm{PO}$ system with PPG by inducing phase separation during sol-gel reaction and by fixing transitional structure of phase separation by gelation. A small molecular weight PPG with 6 or 7 monomer units is enough for inducing phase separation during sol-gel reaction because of its hydrophobic characters. The morphologies of obtained alumina gel can be controlled by changing composition in the solution.

Acknowledgements The authors thank the Advanced Research Support Center of Ehime University for technical assistance. This work was supported by JSPS KAKENHI Grant Number JP 26420708 .

\section{References}

1) S. Sato, R. Takahashi, T. Sodesawa, N. Honda and H. Shimizu, Catal. Commun., 4, 77-81 (2003).

2) L. B. Avdeeva, O. V. Goncharova, D. I. Kochubey, V. I. Zaikovskii, L. M. Plyasova, B. N. Novgorodov and Sh. K. Shaikhutdinov, Appl. Catal., A-Gen., 141, 117-129 (1996).

3) W. Cai, J. Yu, C. Anand, A. Vinu and M. Jaroniec, Chem. Mater, 23, 1147-1157 (2011)

4) C. J. Brinker and G. W. Scherer, "Sol-Gel Science, The Physics and Chemistry of Sol-Gel Processing", Academic Press, San Diego (1990) pp. 59-82.

5) R. Takahashi, S. Sato, T. Sodesawa, M. Kawakita and K. Ogura, J. Phys. Chem. B, 104, 12184-12191 (2000).

6) S. H. Joo, S. J. Choi, I. Oh, J. Kwak, Z. Liu, O. Terasaki and R. Ryoo, Nature, 412, 169-172 (2001).

7) H. Arai and M. Machida, Appl. Catal., 138, 161-176 (1996).

8) T. V. Gestel, C. Vandecasteele, A. Buekenhoudt, C. Dotremont, J. Luyten, R. Leysen, B. V. Bruggen and G. Maes, J. Membrane Sci., 207, 73-89 (2002).

9) F. Vaudry, S. Khodabandeh and M. E. Davis, Chem. Mater., 8, 1451-1464 (1996).

10) K. Kamiya, J. Yotani, R. Senba, J. Matsuoka and H. Nasu, J. Ceram. Soc. Jpn., 104, 658-687 (1996).

11) A. E. Gash, T. M. Tillotson, J. H. Satcher, Jr., L. W. Hrubesh and R. L. Simpson, J. Non-Cryst. Solids, 285, 22-28 (2001).

12) T. F. Baumann, A. E. Gash, S. C. Chinn, A. M. Sawvel, R. S. Maxwell and J. H. Satcher, Jr., Chem. Mater., 17, 395-401 (2005).

13) A. E. Gash, T. M. Tillotson, J. H. Satcher, Jr., J. F. Poco, L. W. Hrubesh and R. L. Simpson, Chem. Mater., 13, 999-1007 (2001).

14) Y. Tokudome, K. Fujita, K. Nakanishi, K. Miura and K. Hirao, Chem. Mater., 19, 3393-3398 (2007).

15) K. Nakanishi and N. Tanaka, Accounts Chem. Res., 40, 863873 (2007).

16) R. Takahashi, S. Sato, T. Sodesawa, K. Arai and M. Yabuki, J. Catal., 229, 24-29 (2005)

17) Y. Matsumura and T. Nakamori, Appl. Catal., A-Gen., 258, 107-114 (2004).

18) R. Takahashi, K. Nakanishi and N. Soga, J. Sol-Gel Sci. Techn., 8, 71-76 (1997).

19) R. Takahashi, K. Nakanishi and N. Soga, J. Ceram. Soc. Jpn., 106, 772-777 (1998). 